\title{
Novel Bacterial Surface Display System Based on the Escherichia coli Protein MipA
}

\author{
Mee-Jung Han* \\ Department of Biomolecular and Chemical Engineering, and Department of Nursing, Dongyang University, \\ Yeongju 36040, Republic of Korea
}

\begin{abstract}
Bacterial surface display systems have been developed for various applications in biotechnology and industry. Particularly, the discovery and design of anchoring motifs is highly important for the successful display of a target protein or peptide on the surface of bacteria. In this study, an efficient display system on Escherichia coli was developed using novel anchoring motifs designed from the $E$. coli mipA gene. Using the $C$-terminal fusion system of an industrial enzyme, Pseudomonas fluorescens lipase, six possible fusion sites, $V^{140}, V^{176}, K^{179}, V^{226}, V^{232}$, and $K^{234}$, which were truncated from the C-terminal end of the mipA gene $\left(M^{140}, M^{176}, M V^{179}, M V^{226}, M V^{232}\right.$, and $\left.M V^{234}\right)$ were examined. The whole-cell lipase activities showed that $M V^{140}$ was the best among the six anchoring motifs. Furthermore, the lipase activity obtained using $M V^{140}$ as the anchoring motif was approximately 20 -fold higher than that of the previous anchoring motifs FadL and OprF but slightly higher than that of YiaTR232. Western blotting and confocal microscopy further confirmed the localization of the fusion lipase displayed on the $E$. coli surface using the truncated $\mathbf{M V}^{140}$. Additionally the $\mathbf{M V}^{140}$ motif could be used for successfully displaying another industrial enzyme, a-amylase from Bacillus subtilis. These results showed that the fusion proteins using the $\mathbf{M V}^{140}$ motif had notably high enzyme activities and did not exert any adverse effects on either cell growth or outer membrane integrity. Thus, this study shows that MipA can be used as a novel anchoring motif for more efficient bacterial surface display in the biotechnological and industrial fields.
\end{abstract}

Keywords: E. coli MipA, cell surface display, outer membrane protein

Received: January 31,2020 Accepted: April 19, 2020

First published online: April 23, 2020

*Corresponding author Phone: +82-54-630-1148 Fax: +82-54-630-1275 E-mail:mjhan75@dyu.ac.kr

pISSN 1017-7825 elSSN 1738-8872

Copyright(C) 2020 by The Korean Society for Microbiology and Biotechnology

\section{Introduction}

Bacterial surface display is a protein engineering technique used for display of a target, such as a peptide or protein (enzyme) on the surface of bacteria. Bacterial cell surface display systems have been employed for various biotechnological and industrial applications, such as whole-cell biocatalysts, biosensors, bioabsorbents and affinity-based screening, antibody epitope mapping, and vaccine delivery [1-3]. In particular, Escherichia coli display systems have been widely used as bioabsorbents and biosensors in the bioremediation of pollutants and toxic materials $[4,5]$, or as biocatalysts in biofuel and chemical production by the enzymatic transformation of chemicals to produce enantiomerically pure compounds [6-9].

However, the $E$. coli display system encounters difficulty in displaying a large protein stably and with the correct steric conformation because the protein must pass through two membrane layers and then undergo protein targeting. Thus, the choice and design of anchoring motifs are highly important for the stability of cell envelope integrity. Various anchoring motifs, including outer membrane proteins, lipoproteins, autotransporters, subunits of surface appendages, and S-layer proteins, were examined [1, 10, 11]. Most importantly, bacterial outer membrane proteins, such as FadL, LamB, Lpp-OmpA, OmpA, OmpC, OmpF, OmpS, OmpX, OmpW, OprF, PhoE, and YiaT, have been employed for displaying various peptides and proteins, including antibodies, domains, enzymes, and receptors [12-16]. However, each anchoring motif has been found to have different capacities for protein display, making it necessary to develop appropriate anchoring motifs depending on individual proteins of various sizes and characteristics [1,17]. The majority of the previously developed systems are only suitable for peptides or relatively small polypeptides $[1,18]$. Larger proteins could be displayed as anchoring motifs, such as Pseudomonas aeruginosa OprF [9], E. coli FadL [8], OmpX [19] and YiaT [20]. Therefore, the success of a cell surface display system is highly dependent on the choice of an anchoring motif that is appropriate for the intended target protein.

In this study, we developed an efficient $E$. coli cell surface display using a novel anchoring motif truncated from the E. coli MltA-interacting protein (MipA; Swiss-Prot no. P0A908) at the C-terminus. To determine the best anchoring motif from MipA, several possible motifs were tested by creating truncated mipA genes to link the function of a protein, specifically a highly thermostable lipase from Pseudomonas fluorescens SIK W1 (49.9 kDa) using a C-terminus deletion strategy. Additionally, the display efficiency of lipase using the truncated MipA motif 
Table 1. The bacterial strains and plasmids used in this study.

\begin{tabular}{|c|c|c|}
\hline $\begin{array}{l}\text { Strain or } \\
\text { plasmid }\end{array}$ & Relevant characteristics & $\begin{array}{l}\text { Reference } \\
\text { or source }\end{array}$ \\
\hline \multicolumn{3}{|l|}{ E. coli strains } \\
\hline XL1-Blue & 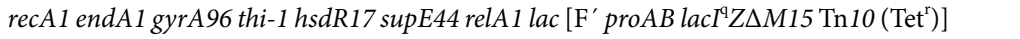 & Stratagene $\mathrm{a}^{\mathrm{a}}$ \\
\hline XL10-Gold & $\begin{array}{l}\operatorname{Tet}^{\mathrm{r}} \Delta(m c r A) 183 \Delta(m c r C B-h s d S M R-m r r) 173 \text { endA1 supE44 thi-1 recA1 gyrA } 96 \text { relA1 lac Hte } \\
{\left[\mathrm{F}^{\prime} \text { proAB } \text { lacl }^{\mathrm{q}} Z \Delta M 15 \mathrm{Tn} 10\left(\mathrm{Tet}^{\mathrm{r}}\right) \text { Amy Cam }{ }^{\mathrm{r}}\right]}\end{array}$ & Stratagene $^{\mathrm{a}}$ \\
\hline \multicolumn{3}{|c|}{ : } \\
\hline $\mathrm{p} \operatorname{Trc} 99 \mathrm{~A}$ & $4.2 \mathrm{~kb} ; \mathrm{Ap}^{\mathrm{r}}$, $\operatorname{trc}$ promoter & Pharmacia \\
\hline $\mathrm{p} \operatorname{TrcM}$ & $4.9 \mathrm{~kb} ; \mathrm{p} \operatorname{Trc} 99 \mathrm{~A}$ derivative containing full-length $747 \mathrm{bp}$ fragment of E. coli mipA & This study \\
\hline $\mathrm{pTrcMV}^{140}$ & $4.6 \mathrm{~kb} ; \mathrm{p} \operatorname{Trc} 99 \mathrm{~A}$ derivative containing $420 \mathrm{bp}$ fragment of E. coli mipA & This study \\
\hline $\mathrm{pTrcMV}^{176}$ & $4.7 \mathrm{~kb}$; $\mathrm{p} \operatorname{Trc} 99 \mathrm{~A}$ derivative containing $528 \mathrm{bp}$ fragment of $E$. coli mipA & This study \\
\hline $\mathrm{p} \operatorname{TrcMK} \mathrm{M}^{179}$ & $4.7 \mathrm{~kb} ; \mathrm{p} \operatorname{Trc} 99 \mathrm{~A}$ derivative containing $537 \mathrm{bp}$ fragment of $E$. coli mipA & This study \\
\hline $\mathrm{p} \operatorname{TrcMV} \mathrm{V}^{226}$ & $4.9 \mathrm{~kb} ; \mathrm{p} \operatorname{Trc} 99 \mathrm{~A}$ derivative containing $678 \mathrm{bp}$ fragment of $E$. coli mipA & This study \\
\hline $\mathrm{p} \operatorname{TrcMV} \mathrm{V}^{232}$ & $4.9 \mathrm{~kb} ; \mathrm{p} \operatorname{Trc} 99 \mathrm{~A}$ derivative containing $696 \mathrm{bp}$ fragment of E. coli mipA & This study \\
\hline $\mathrm{p} \operatorname{TrcMK} \mathrm{MK}^{234}$ & $4.9 \mathrm{~kb} ; \mathrm{p} \operatorname{Trc} 99 \mathrm{~A}$ derivative containing $702 \mathrm{bp}$ fragment of E. coli mipA & This study \\
\hline pTrcMV ${ }^{140} \mathrm{PL}$ & $6.0 \mathrm{~kb} ; \mathrm{p} \operatorname{TrcMV} \mathrm{V}^{140}$ derivative containing $P$. fluorescens SIK W1 lipase gene fused with FLAG-tag & This study \\
\hline $\mathrm{p} \operatorname{TrcMV}{ }^{176} \mathrm{PL}$ & $6.1 \mathrm{~kb} ; \mathrm{p} \operatorname{TrcMV} \mathrm{V}^{176}$ derivative containing $P$. fluorescens SIK W1 lipase gene fused with FLAG-tag & This study \\
\hline $\mathrm{p} \operatorname{TrcMK}{ }^{179} \mathrm{PL}$ & $6.1 \mathrm{~kb} ; \mathrm{p} \operatorname{TrcMV}{ }^{179}$ derivative containing $P$. fluorescens SIK W1 lipase gene fused with FLAG-tag & This study \\
\hline $\mathrm{p} \operatorname{TrcMV}{ }^{22} \mathrm{PL}$ & $6.3 \mathrm{~kb} ; \mathrm{p} \operatorname{TrcMV} \mathrm{V}^{226}$ derivative containing P. fluorescens SIK W1 lipase gene fused with FLAG-tag & This study \\
\hline p TrcMV ${ }^{232} \mathrm{PL}$ & $6.3 \mathrm{~kb} ; \mathrm{p} \operatorname{TrcMV} \mathrm{V}^{232}$ derivative containing $P$. fluorescens SIK W1 lipase gene fused with FLAG-tag & This study \\
\hline $\mathrm{p} \operatorname{TrcMK}{ }^{234} \mathrm{PL}$ & $6.3 \mathrm{~kb} ; \mathrm{p} \operatorname{TrcMK} \mathrm{M}^{234}$ derivative containing P. fluorescens SIK W1 lipase gene fused with FLAG-tag & This study \\
\hline pTrcMV ${ }^{140} \mathrm{BA}$ & $5.9 \mathrm{~kb} ; \mathrm{p} \operatorname{TrcMV}{ }^{140}$ derivative containing $B$. subtilis $\alpha$-amylase gene fused with FLAG-tag & This study \\
\hline
\end{tabular}

${ }^{\mathrm{a}}$ Stratagene Cloning System, USA.

${ }^{\mathrm{b}}$ Pharmacia Biotech, Uppsala, Sweden.

was compared with those of the previous anchoring motifs, FadL [8], OrpF [9], and YiaT [20]. Furthermore, the best truncated MipA motif was employed to display another enzyme, $\alpha$-amylase from Bacillus subtilis $(47.3 \mathrm{kDa})$, which hydrolyzes large $\alpha$-linked polysaccharides, such as starch or glycogen, into fermentable sugars.

\section{Materials and Methods}

\section{Bacterial Strains and Culture Conditions}

Table 1 shows all bacterial strains and plasmids employed in this study. E. coli XL-1 Blue was used as the host strain for general cloning, while E. coli XL10-Gold was used as the host strain for the cell surface display studies. E. coli cells were cultivated at $37^{\circ} \mathrm{C}$ and $250 \mathrm{rpm}$ in a 250 -ml flask containing $100 \mathrm{ml}$ of Luria-Bertani (LB) medium composed of $10 \mathrm{~g} / \mathrm{l}$ bacto-tryptone, $5 \mathrm{~g} / \mathrm{l}$ bacto-yeast extract, and $5 \mathrm{~g} / \mathrm{l} \mathrm{NaCl}$. For cultivation of recombinant $E$. coli cells harboring a plasmid, the medium was supplemented with ampicillin $(50 \mu \mathrm{g} / \mathrm{ml})$. Cell growth was monitored by measuring the optical density at $600 \mathrm{~nm}\left(\mathrm{OD}_{600}\right)$ using a spectrophotometer (Beckman DU 650, USA). At an $\mathrm{OD}_{600}$ of 0.4 , the cells were induced to display lipase as a target protein by the addition of $1 \mathrm{mM}$ isopropyl- $\beta$-Dthiogalactopyranoside (IPTG). After induction, the cells were cultured for an additional $4 \mathrm{~h}$ at $30^{\circ} \mathrm{C}$ and then used for further analyses.

\section{DNA Manipulation}

Table 2 shows the primers used in this study. Polymerase chain reaction (PCR) to amplify target genes described in Table 2 was performed with a PCR Thermal Cycler MP (Takara Shuzo Co., Ltd., Japan) using the Expand High Fidelity PCR System (Roche Molecular Biochemicals, Germany). DNA sequencing was carried out using the BigDye Terminator Cycle Sequencing Kit (Perkin-Elmer Co., USA) with Taq polymerase and an ABI Prism 377 DNA sequencer (Perkin-Elmer Co.). All DNA manipulations, including digestion of restriction enzymes, ligation, and agarose gel electrophoresis, were performed according to standard procedures [21].

\section{SDS-PAGE and Immunoblotting}

To confirm an enzyme display on the E. coli surface, the outer membrane proteins were prepared by sodium lauryl sarcosinate (sarcosine) enrichment, as previously described by Lee et al. $[8,9]$. The outer membrane fractions were analyzed by $10 \%$ sodium dodecyl sulfate-polyacrylamide gel electrophoresis (SDS-PAGE). An immunoblotting experiment was performed in our previous study [22]. The proteins were transferred to Immobilon-P PVDF membranes (Millipore); the membranes were stained with MemCode reversible protein stain (Pierce Biotechnology) and imaged to verify that the protein loads were uniform and to ensure that efficient electrotransfer occurred, and the membranes were destained with Milli-Q water and blocked with nonfat dry milk prior to incubation with each primary antibody. For the immunodetection of the fusion protein, a monoclonal ANTI-FLAG M2 antibody (Sigma-Aldrich Co., USA) and a goat anti-mouse immunoglobulin G (IgG)horseradish peroxidase (HRP) conjugate (Sigma-Aldrich) were used. An enhanced chemiluminescence (ECL) kit (Amersham ECL Prime Western Blotting Detection Reagent; GE Healthcare Bio-Sciences AB, Sweden) was used for signal detection. 
Table 2. The list of primers used in the PCR experiments.

\begin{tabular}{|c|c|c|c|}
\hline Primer no. & Sequence $^{\mathrm{a}}$ & Gene to be amplified & Template \\
\hline 1 & 5-ggaattcATGACCAAACTCAAACTTCTGGCA & Full-length mipA gene & E. coli W3110 \\
\hline 2 & 5-gctctagaTCAGAATTTGTAGGTGATCCCGGT & & chromosome \\
\hline 3 & 5-ggaattcATGACCAAACTCAAACTTCTGGCA & Truncated mipA at $\mathrm{Val}^{140}$ & E. coli W3110 \\
\hline 4 & 5-gctctagaGACGATGCCGTTGCTGTTATCC & position & chromosome \\
\hline 5 & 5-ggaattcATGACCAAACTCAAACTTCTGGCA & Truncated mipA at $\mathrm{Val}^{176}$ & E. coli W3110 \\
\hline 6 & 5-gctctagaTACGCCATAATAGTATTCGTTCTG & position & chromosome \\
\hline 7 & 5-ggaattcATGACCAAACTCAAACTTCTGGCA & Truncated mipA at Lys ${ }^{179}$ & E. coli W3110 \\
\hline 8 & 5-gctctagaTTTGCGCGATACGCCATAATAGTA & position & chromosome \\
\hline 9 & 5-ggaattcATGACCAAACTCAAACTTCTGGCA & Truncated mipA at $\mathrm{Val}^{226}$ & E. coli W3110 \\
\hline 10 & 5-gctctagaAACTTCATCAGACAGACGGGTGTA & position & chromosome \\
\hline 11 & 5-ggaattcATGACCAAACTCAAACTTCTGGCA & Truncated mipA at $\mathrm{Val}^{232}$ & E. coli W3110 \\
\hline 12 & 5-gctctagaCACCATCGGGCTGTCAGTAACTTC & position & chromosome \\
\hline 13 & 5-ggaattcATGACCAAACTCAAACTTCTGGCA & Truncated mipA at Lys ${ }^{234}$ & E. coli W3110 \\
\hline 14 & 5-gctctagaTTTATCCACCATCGGGCTGTCAGT & position & chromosome \\
\hline 15 & 5-gctctagaATGGGTGTATTTGACTACAAGAAC & P. fluorescens SIK W1 lipase & P. fluorescens SIK \\
\hline 16 & $\begin{array}{l}\text { 5-cccaagcttTTACTTGTCGTCATCGTCCTTGTAG } \\
\text { TCACTGATCAGCACACC }\end{array}$ & gene fused with FLAG tag & $\begin{array}{l}\text { W1 chromosome } \\
{[28,29]}\end{array}$ \\
\hline
\end{tabular}

${ }^{a}$ Restriction enzyme sites are shown in bold.

tliA, which encodes a thermostable lipase $(476 \mathrm{aa} ; 49.9 \mathrm{kDa})$.

\section{Immunofluorescence Microscopy}

For fluorescence imaging, cells induced with $1 \mathrm{mM}$ IPTG for $4 \mathrm{~h}$ were harvested by centrifugation for $5 \mathrm{~min}$ at $3,500 \times g$ and $4^{\circ} \mathrm{C}$ and then washed with phosphate-buffered saline (PBS). The cells were incubated with the ANTI-FLAG M2 antibody conjugated with fluorescein isothiocyanate (FITC) (Sigma-Aldrich) diluted 1:500 in PBS containing 3\% (wt/vol) BSA at $25^{\circ} \mathrm{C}$ for $2 \mathrm{~h}$. Prior to microscopic observation, the cells were washed three times with PBS to remove unbound antibody probes. The cells were mounted on poly-L-lysine-coated microscopic slide glasses and examined by confocal microscopy (Carl Zeiss, Germany). Photographs were taken with a Carl Zeiss LSM 410. The samples were excited at $488 \mathrm{~nm}$, and the images were filtered by a longpass $505-\mathrm{nm}$ filter.

\section{Measurement of Enzymatic Activities}

The activity of the $P$. fluorescens lipase was determined by a spectrophotometric method using $p$-nitrophenyl decanoate (MW 293.36) as the substrate, as previously described by Lee et al. [8,9]. After cultivation, cells were harvested by centrifugation at $3,500 \times g$ and $4^{\circ} \mathrm{C}$ and then washed twice with PBS. Lyophilized cells were added to $3 \mathrm{ml}$ of a substrate solution with a volumetric ratio of 1 part $10 \mathrm{mM} p$-nitrophenyl decanoate in acetonitrile, 4 parts ethanol and 95 parts $50 \mathrm{mM}$ Tris- $\mathrm{HCl}$. The reaction mixture was incubated at $37^{\circ} \mathrm{C}$ for $10 \mathrm{~min}$, and the reaction was terminated by the addition of $2 \mu \mathrm{l}$ of $0.5 \mathrm{M}$ EDTA. The activity was determined by measuring the absorbance at $405 \mathrm{~nm}$ using a spectrophotometer. One unit of lipase activity was defined as the amount of enzyme releasing $1 \mu \mathrm{mol}$ of $p$-nitrophenol per minute.

The activity of $B$. subtilis a-amylase was measured using an EnzyChrom a-Amylase Assay Kit (ECAM-100; BioAssay Systems, USA). Cells induced with $1 \mathrm{mM}$ IPTG for $4 \mathrm{~h}$ were harvested by centrifugation for $5 \mathrm{~min}$ at $3,500 \times g$ and $4^{\circ} \mathrm{C}$ and then washed with MilliQ water, and transferred to a clear, flat-bottomed 96-well plate. The first reaction was carried out using starch as a substrate at room temperature (RT) for $15 \mathrm{~min}$, followed by adding the detection reagent to each 96-well plate and incubation for $20 \mathrm{~min}$ at RT. Sample background readings were measured with an assay buffer ( $\mathrm{pH} 7.0$ ) at $585 \mathrm{~nm}$, and $400 \mu \mathrm{M}$ glucose was used as a standard. The $\alpha$-amylase activity is calculated as:

$$
\text { Activity }=\left[\left(\mathrm{OD}_{\text {Sample }}-\mathrm{OD}_{\text {Buffer }}\right) \times 400 \times \mathrm{n}\right] /\left[\left(\mathrm{OD}_{\mathrm{STD}}-\mathrm{OD}_{\text {Buffer }}\right) \times \mathrm{t}(\mathrm{min})\right](\mathrm{U} / \mathrm{L})
$$

In this formula, $\mathrm{OD}_{\text {Sample, }}, \mathrm{OD}_{\mathrm{STD}}$, and $\mathrm{OD}_{\text {Buffer }}$ are the optical density values of the sample, the $400 \mu \mathrm{M}$ glucose standard and assay buffer, respectively, $t$ is the incubation time, and $n$ is the dilution factor. One unit (U) was defined as the amount of enzyme required to produce $1 \mu \mathrm{mol}$ of glucose per minute under the assay conditions.

All activity assays were independently performed in triplicate, and the standard deviations were determined.

\section{Results and Discussion}

\section{Design of the E. coli Surface Display System Using an mipA Gene}

The function of E. coli MipA has not been well characterized to date, except that MipA may be implicated in antibiotic resistance in the E. coli outer membrane [23]. By BLAST analysis, MipA and OmpV were determined to be highly homologous and to belong to the MipA/OmpV family. However, our previous study of the outer membrane proteome showed that MipA was continually expressed in both E. coli K-12 and B strains [24]. Additionally, other researchers identified MipA by proteome analysis of the E. coli outer membrane [25,26]. Thus, MipA has been considered to engineer an outer membrane anchoring element for bacterial cell surface display due to its continuous expression independent of E. coli strains. 


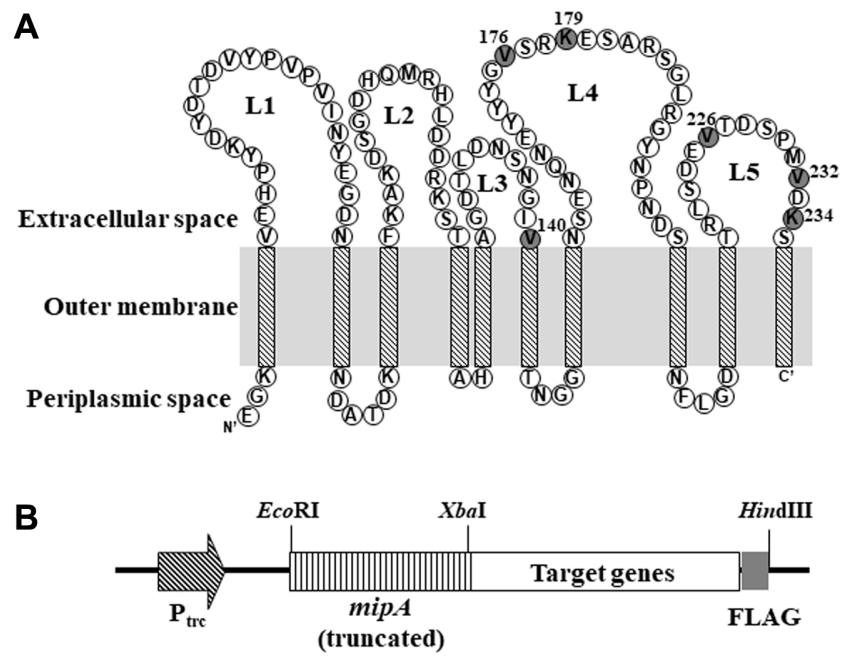

Fig. 1. Construction of the MipA-fused display system. (A) The structure of MipA in the E. coli outer membrane. This topology was an arbitrary redrawing of the image predicted by PRED-TMBB [27]. Each gray circle indicates the fusion position of MipA with lipase: $\mathrm{V}^{140}$ in the third extracellular loop; $\mathrm{V}^{176}$ and $\mathrm{K}^{179}$ in the fourth extracellular loop; and $\mathrm{V}^{226}, \mathrm{~V}^{232}$, and $\mathrm{K}^{234}$ in the fifth extracellular loop. (B) A schematic diagram of the expression system for MipA-fused target genes.

The outer membrane topology of MipA was first predicted using PRED-TMBB (http://bioinformatics.biol. uoa.gr/PRED-TMBB/) [27]. As shown in Fig. 1A, the MipA protein contains five extracellular loops that form a $\beta$ sheet protruding from the cell surface. Among these loops, the third, fourth and fifth loops were primarily considered, since they likely have stronger and more stable anchoring locations in the $\beta$-barrel structure of $E$. coli. In this study, a C-terminal truncation strategy was used to display the protein of interest, and six cleavage sites $\left(\mathrm{V}^{140}, \mathrm{~V}^{176}, \mathrm{~K}^{179}, \mathrm{~V}^{226}, \mathrm{~V}^{232}\right.$, and $\left.\mathrm{K}^{234}\right)$ of the mipA gene were tested as possible fusion sites from loops 3,4 and 5 exposed on the exterior of the outer membrane. P. fluorescens SIK W1 lipase $(49.9 \mathrm{kDa})$ was examined as a model protein for display on bacterial surfaces due to its various applications in biocatalysis and bioremediation $[5,9,13,14]$.

\section{Construction of the Lipase Display System on the E. coli Surface}

For construction of expression systems composed of truncated MipA fused to a target protein (Fig. 1B), the fulllength mipA gene, as well as the C-terminal truncated mipA (mipAt) genes encoding the first 140, 176, 179, 226, 232 and 234 amino acids from the N-terminus, were amplified by PCR using the primers shown in Table 2 . The genes were cloned into the EcoRI and XbaI sites of p Trc99A to make $\mathrm{p} \operatorname{TrcM}, \mathrm{p} \operatorname{TrcMV}{ }^{140}, \mathrm{p} \operatorname{TrcMV}{ }^{176}, \mathrm{p} \operatorname{TrcMK}{ }^{179}$, $\mathrm{pTrcMV}^{226}, \mathrm{pTrcMV}^{232}$, and $\mathrm{pTrcMK}{ }^{234}$, respectively. To create a restriction enzyme site (XbaI) at the $3^{\prime}$ end of the mipAt gene, two amino acids (Ser and Arg) were added at the C-terminus. The full-length mipA gene without fusion ( $\mathrm{p} \operatorname{TrcM}$ ) was used as a control.

To display a lipase on the $E$. coli cell surface, the $P$. fluorescens lipase gene containing the FLAG sequence (DYKDDDDK) was amplified using primers 15 and 16; it was then cloned into the XbaI and HindIII sites of the

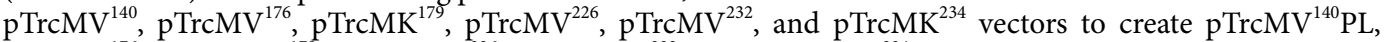
p TrcMV ${ }^{176} \mathrm{PL}, \mathrm{p} \operatorname{TrcMK}{ }^{179} \mathrm{PL}$, p TrcMV ${ }^{226} \mathrm{PL}, \mathrm{p} \operatorname{TrcMV}{ }^{232} \mathrm{PL}$, and $\mathrm{p} \operatorname{TrcMK}{ }^{234} \mathrm{PL}$, respectively. E. coli XL10-Gold was used as a host strain for display because XL10-Gold was the best $E$. coli host strain, as reported by several previous display studies $[8,9,20]$.

\section{Lipase Activity on the E. coli Surface}

To test which anchoring motif of the mipA-truncated derivatives developed in this study is the most efficient display system for displaying a large protein on $E$. coli cells, we first examined the enzymatic activities of the lipase displayed on several recombinant E. coli cells. The specific whole-cell lipase activities of recombinant cells are shown in Fig. 2. The results showed that lipase activity could be measured from all recombinant $E$. coli display strains to varying degrees, except for a control. Among the six mipA derivatives, $\mathrm{MV}^{140}$ was the best display motif. These results suggest that lipase was successfully and efficiently displayed in an active form with high stability using the mipAt gene as an anchoring motif. In addition, lipase activity obtained using $\mathrm{MV}^{140}$ was approximately 20 -fold higher than those obtained with the previous anchoring motifs OprF or FadL display systems, which were applied as enantioselective biocatalysts for organic synthesis $[8,9]$. Furthermore, the display efficiency of the $\mathrm{MV}^{140}$-fused lipase on the membrane of $E$. coli had a slightly better efficiency than that of the YiaTR232-fused lipase [20], which was one of the more efficient $E$. coli display systems. These results suggest that the anchoring motif created using truncated MipA provides another efficient way to display functional lipase on the surface of E. coli.

Confirmation of Lipase Display on the E. coli Surface 


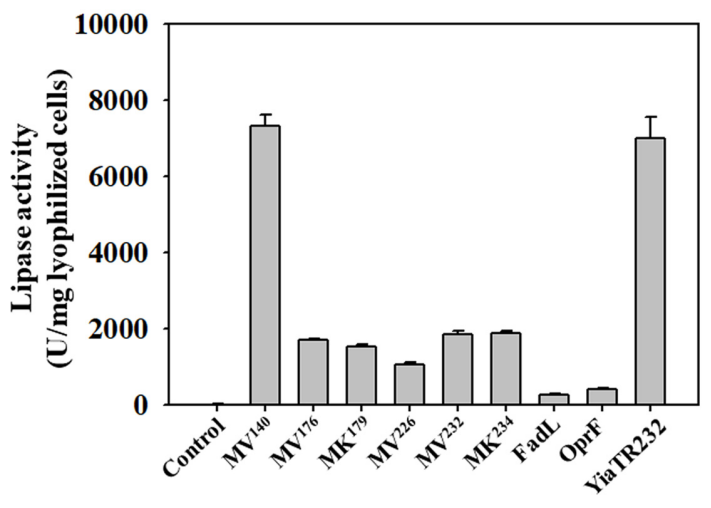

Fig. 2. Comparison of lipase activity between the MipA anchoring motifs developed in this study and the previously reported motifs FadL [8], OprF [9], and YiaT [20]. E. coli XL10-Gold (pTrcM) is indicated as a control. All activity assays were independently performed in triplicate, and the standard deviations were determined. One unit $(\mathrm{U})$ of lipase activity was defined as the amount of enzyme that releases $1 \mu \mathrm{mol}$ of $p$-nitrophenol per minute.

To confirm that localization of lipase was displayed on the surface using $\mathrm{MV}^{140}$ as an anchoring motif, the total lysate, outer membrane proteins, and soluble protein fractions of the E. coli XL 10-Gold cells harboring pTrcMV ${ }^{140} \mathrm{PL}$ were analyzed by SDS-PAGE and western blotting (Fig. 3 ). No signal was detected in the E. coli cells harboring the control $\mathrm{p} \operatorname{TrcM}$. In contrast, the bands for the approximately $65-\mathrm{kDa}$ fusion lipase proteins were clearly detected in the total lysate and outer membrane fractions of the recombinant $E$. coli cells harboring pTrcMV ${ }^{140} \mathrm{PL}$ on the Coomassie Blue-stained SDS-PAGE gel (Fig. 3A). Additionally, the amount and localization of $\mathrm{MV}^{140}$-fused lipase on membrane fractions were clearly confirmed by western blotting (Fig. 3B). These results show that the fusion lipase tagged with FLAG was successfully displayed on the E. coli surface. However, the localization of excess proteins on the outer membrane might cause problems in cell wall integrity and could consequently result in cell lysis and the possible release of anchored proteins into the culture medium. Thus, the culture supernatant of E. coli harboring $\mathrm{p} \operatorname{TrcMV}^{140} \mathrm{PL}$ was analyzed by western blotting analysis, but no signal was detected. These results indicate that $\mathrm{MV}^{140}$-fused lipases were displayed on the surface with a minimum of cell lysis.

\section{Confocal Microscopic Analysis of Lipase Display on the E. coli Surface}

Additionally, the localization of lipase was confirmed by confocal microscopy. After cultivation, the cells were labeled with FITC-conjugated anti-FLAG antibody probe, which can recognize the FLAG tag linked to the Cterminus of lipase. E. coli harboring p TrcMV ${ }^{140} \mathrm{PL}$ showed strong fluorescence, while E. coli harboring pTrcM did not show any fluorescence signal (Fig. 4). This finding means that the $\mathrm{MV}^{140}$ anchoring motif successfully mediated the localization of lipase on the surface of E. coli. This result is almost consistent with the results of enzyme activity and western blotting of the $\mathrm{MV}^{140}$-fused lipase on the outer membrane of E. coli (Figs. 2 and 3).

\section{Display of $\alpha$-Amylase on the E. coli Surface Using the $\mathrm{MV}^{140}$ as an Anchoring Motif}

To demonstrate the general use of $\mathrm{MV}^{140}$ motif, $B$. subtilis $\alpha$-amylase was examined as another model protein for cell surface display. First, the B. subtilis a-amylase gene containing the FLAG sequence was obtained from pTrcYiaTR ${ }_{232} \mathrm{BA}[20]$ with digestion of the XbaI and HindIII and then cloned into the same sites of the $\mathrm{pTrcMV}^{140}$
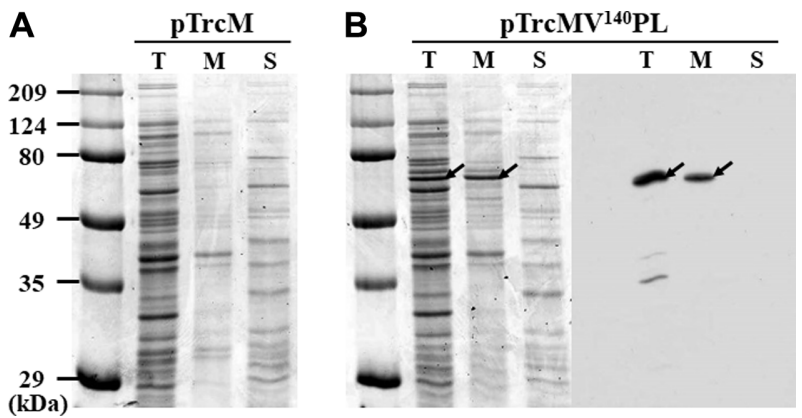

Fig. 3. SDS-PAGE and western blotting analyses for total, outer membrane, and soluble fractions from $E$. coli XL10-Gold harboring pTrcM (control) (A) and pTrcMV ${ }^{140}$ PL (B). First lane in each gel indicates the molecular weight size markers $(\mathrm{kDa})$. $\mathrm{T}$, whole cell lysate; $\mathrm{M}$, outer membrane protein fractions; and $\mathrm{S}$, soluble proteins. Arrows indicate the $\mathrm{MV}^{140}$-fused lipase. 


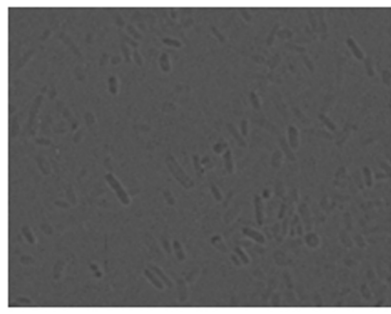

pTrcM
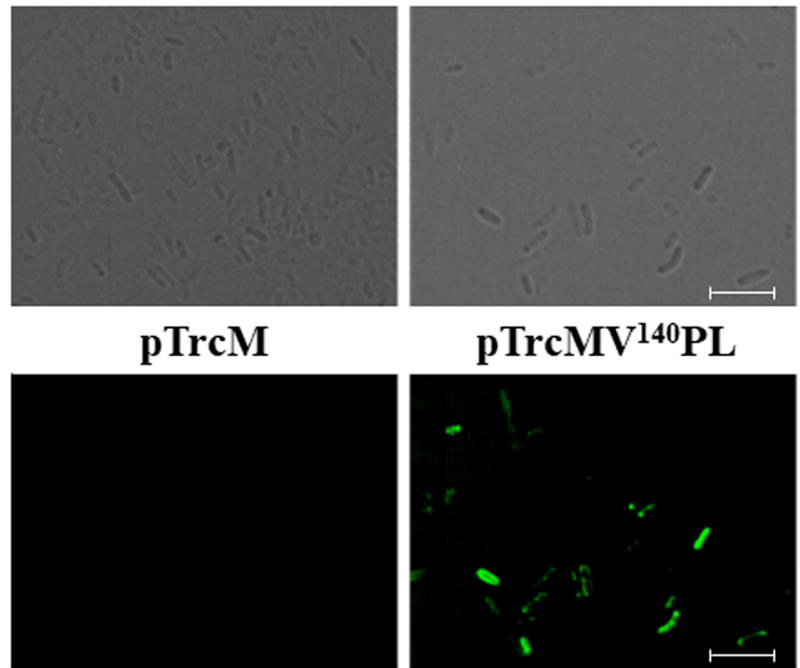

pTrcMV ${ }^{140} \mathrm{PL}$

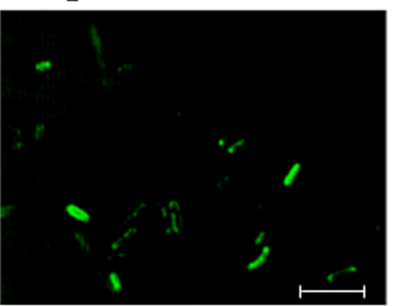

Fig. 4. Differential interference microscope images (upper) and confocal immunofluorescence microscope images (lower) of $E$. coli XL10-Gold cells harboring pTrcM (control; left images) and pTrcMV ${ }^{140} \mathrm{PL}$ (right images). Each scale bar represents $5 \mu \mathrm{m}$.

vector to make $\operatorname{TrcMV}^{140} \mathrm{BA}$ (Table 1). Confirmation of the display of $\alpha$-amylase was conducted by analyzing the western blotting of the outer membrane proteins of E. coli XL10-Gold cells harboring p $\operatorname{TrcMV}^{140} \mathrm{BA}$. The result showed that approximately $63-\mathrm{kDa}$ fusion proteins were detected in the outer membrane fractions of $E$. coli XL10Gold (pTrcMV ${ }^{140} \mathrm{BA}$ ) (Fig. 5A). However, no signal was detected in the E. coli cells harboring the control pTrcM.

Next, we examined whether the displayed $\alpha$-amylase proteins were active. The specific whole-cell $\alpha$-amylase activities of the recombinant $E$. coli cells are shown in Fig. 5B. As expected, the specific activity of $\alpha$-amylase in the E. coli cells harboring the control pTrcM was not measured. Also, the $\alpha$-amylase activities were negligible in the supernatants of all recombinant cells, suggesting that cell lysis was not a significant problem. The specific activity of $\alpha$-amylase with whole cells was $48 \mathrm{U} / \mathrm{L}$ for E. coli XL10-Gold (pTrcMV ${ }^{140} \mathrm{BA}$ ) cells (Fig. 5B). These results indicate that the $\mathrm{MV}^{140}$ motif could be used for successfully displaying another enzyme, $\alpha$-amylase tagged with FLAG on the E. coli cell surface, but the previous motif, YiaTR232 (55 U/L), was a little more efficient as a display motif for $\alpha$-amylase than the $\mathrm{MV}^{140}$. It demonstrates that the display efficiency could be dependent on the proteins of interest for display although it was used with the same anchoring motif. Therefore, this study shows that MipA can be used as a novel anchoring motif for efficient bacterial surface display in the biotechnological and industrial fields.

In summary, a new cell surface display system was developed using the E. coli MipA protein in this work. To select the best anchoring site from MipA, six possible sites were tested by designing and constructing the lipase fusion display systems. Among these sites, the enzyme activities showed that $\mathrm{MV}^{140}$ was the best anchoring motif for the E. coli display system. Further analyses by SDS-PAGE, western blotting, and confocal microscopy suggested that the $\mathrm{MV}^{140}$ motif could successfully display highly active forms of lipase on the E. coli surface without causing significant defects of cell lysis. In addition, $\alpha$-amylase was also successfully displayed using the $\mathrm{MV}^{140}$-anchoring motif. These two model proteins (lipase and amylase) used in this study could be displayed in
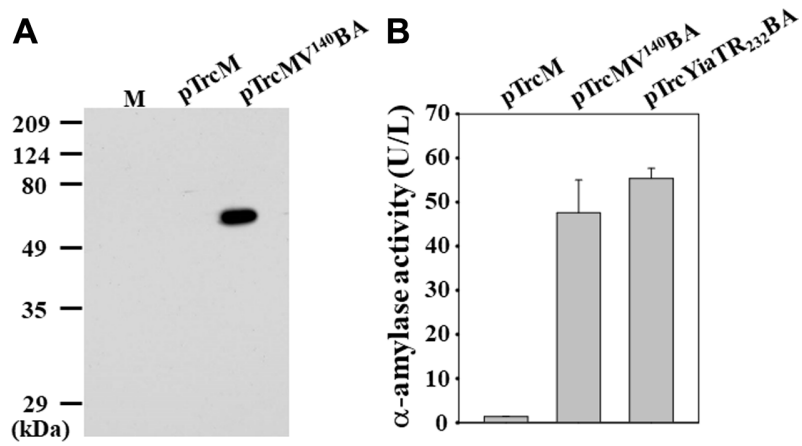

Fig. 5. Display of B. subtilis $\boldsymbol{\alpha}$-amylase on the E. coli cell surface. (A) Western blotting analyses of the outer membrane fractions of E. coli XL10-Gold cells harboring $\mathrm{p} \operatorname{TrcM}$ (control) or $\mathrm{p} \operatorname{TrcMV}{ }^{140} \mathrm{BA}$. M indicates the molecular weight size markers (kDa). (B) The $\alpha$-amylase activity of E. coli XL10-Gold cells harboring p TrcM (control), pTrcMV ${ }^{140} \mathrm{BA}$ or $\mathrm{p} \operatorname{TrcYiaTR}{ }_{232} \mathrm{BA}[20]$. 
active form although they are quite large proteins. However, it might be possible that overexpression of anchoring motifs on the cell surface could result in physiological effects on the rigidity of cell membrane and metabolic burden and then possibly cause cell lysis $[1,30]$. To minimize these deleterious effects of surface display, recombinant E. coli XL10-Gold was cultured in this study at $30^{\circ} \mathrm{C}$ after induction, but these mild conditions (e.g., low temperatures and lower concentrations of the inducer) result in reduced display of target proteins on the surface and consequently lead to reduced activity $[9,31]$. Nevertheless, the mipA-truncated fusion display system developed in this work could be used to efficiently display targets (such as peptides, enzymes or proteins) of interest with an active form in biotechnological and industrial applications.

\section{Acknowledgments}

This study was supported by a grant from Dong Yang University in 2018. The author gratefully acknowledges the technical assistance provided by Hoon Jae Lee.

\section{Conflict of Interest}

The author has no financial conflicts of interest to declare.

\section{References}

1. Lee SY, Choi JH, Xu Z. 2003. Microbial cell-surface display. Trends Biotechnol. 21: 45-52.

2. Wernérus H, Ståhl S. 2004. Biotechnological applications for surface-engineered bacteria. Biotechnol. Appl. Biochem. 40: 209-228.

3. Wu CH, Mulchandani A, Chen W. 2008. Versatile microbial surface-display for environmental remediation and biofuels production. Trends Microbiol. 16: 181-188.

4. Kondo A, Tanaka T, Hasunuma T, Ogino C. 2010. Applications of yeast cell-surface display in bio-refinery. Recent Pat. Biotechnol. 4: 226-234.

5. Kuroda K, Ueda M. 2011. Cell surface engineering of yeast for applications in white biotechnology. Biotechnol. Lett. 33: 1-9.

6. Faber K, Frassen MC. 1993. Prospects for the increased application of biocatalysts in organic transformations. Trends Biotechnol. 11: 461-470.

7. Burton SG, Cowan DA, Woodley JM. 2002. The search for the ideal biocatalyst. Nat. Biotechnol. 20:37-45

8. Lee SH, Choi JI, Park SJ, Lee SY, Park BC. 2004. Display of bacterial lipase on the Escherichia coli cell surface by using FadL as an anchoring motif and use of the enzyme in enantioselective biocatalysis. Appl. Environ. Microbiol. 70: 5074-5080.

9. Lee SH, Choi JI, Han MJ, Choi JH, Lee SY. 2005. Display of lipase on the cell surface of Escherichia coli using OprF as an anchor and its application to enantioselective resolution in organic solvent. Biotechnol. Bioeng. 90: 223-230.

10. Georgiou G, Stathopoulos C, Daugherty PS, Nayak, AR, Iverson BL, Curtiss RI. 1997. Display of heterologous proteins on the surface of microorganisms: from the screening of combinatorial libraries to live recombinant vaccines. Nat. Biotechnol. 15: 29-34.

11. Jung HC, Lebeault JM, Pan JG. 1998. Surface display of Zymomonas mobilis levansucrase by using the ice-nucleation protein of Pseudomonas syringae. Nat. Biotechnol. 16: 576-580.

12. Xu Z, Lee SY. 1999. Display of polyhistidine peptides on the Escherichia coli cell surface by using outer membrane protein C as an anchoring motif. Appl. Environ. Microbiol. 65: 5142-5147

13. Benhar I. 2001. Biotechnological applications of phage and cell display. Biotechnol. Adv. 19: 1-33

14. Samuelson P, Gunneriusson E, Nygren PA, Stahl S. 2002. Display of proteins on bacteria. J. Biotechnol. 96: 129-154.

15. Ko KC, Lee B, Cheong DE, Han Y, Choi JH, Song JJ. 2015. Bacterial cell surface display of a multifunctional cellulolytic enzyme screened from a bovine rumen metagenomic resource. J. Microbiol Biotechnol. 25: 1835-1841.

16. Han MJ, Lee SY, Koh ST, Noh SG, Han WH. 2010. Biotechnological applications of microbial proteomes. J. Biotechnol. 145: $341-349$.

17. Nhan NT, Gonzalez de Valdivia E, Gustavsson M, Hai TN, Larsson G. 2011. Surface display of Salmonella epitopes in Escherichia coli and Staphylococcus carnosus. Microb. Cell Fact. 10: 22

18. van Bloois E, Winter RT, Kolmar H, Fraaije MW. 2011. Decorating microbes: surface display of proteins on Escherichia coli. Trends Biotechnol. 29: 79-86.

19. Yim SS, An SJ, Han MJ, Choi JW, Jeong KJ. 2013. Isolation of a potential anchoring motif based on proteome analysis of Escherichia coli and its use for cell surface display. Appl. Biochem. Biotechnol. 170: 787-804.

20. Han MJ, Lee SH. 2015. An efficient bacterial surface display system based on a novel outer membrane anchoring element from the Escherichia coli protein YiaT. FEMS Microbiol. Lett. 362: 1-7.

21. Sambrook J, Russell DW. 2001. Molecular Cloning: A Laboratory Manual, 3rd Ed. Cold Spring Harbor Laboratory Press, New York.

22. Han MJ, Wang H, Beer LA, Tang HY, Herlyn M, Speicher DW. 2010. A systems biology analysis of metastatic melanoma using indepth three-dimensional protein profiling. Proteomics 10: 4450-4462.

23. Li H, Zhang DF, Lin XM, Peng XX. 2015. Outer membrane proteomics of kanamycin-resistant Escherichia coli identified MipA as a novel antibiotic resistance-related protein. FEMS Microbiol. Lett. 362: 1-8.

24. Han MJ, Lee SY, Hong SH. 2012. Comparative analysis of envelope proteomes in Escherichia coli B and K-12 strains. J. Microbiol. Biotechnol. 22: 470-478.

25. Molloy MP, Herbert BR, Slade MB, Rabilloud T, Nouwens AS, Williams KL, Gooley AA. 2000. Proteomic analysis of the Escherichia coli outer membrane. Eur. J. Biochem. 267:2871-2881.

26. Stenberg F, Chovanec P, Maslen SL, Robinson CV, Ilag LL, von Heijne G, et al. 2005. Protein complexes of the Escherichia coli cell envelope. J. Biol. Chem. 280: 34409-34419.

27. Bagos PG, Liakopoulos TD, Spyropoulos IC, Hamodrakas SJ. 2004. PRED-TMBB: a web server for predicting the topology of betabarrel outer membrane proteins. Nucleic Acids Res. 32: W400-W404.

28. Chung GH, Lee YP, Jeohn GH, Yoo OJ, Rhee JS. 1991. Cloning and nucleotide sequence of thermostable lipase gene from Pseudomonas fluorescens SIK W1. Agric. Biol. Chem. 55: 2359-2365.

29. Ahn JH, Pan JG, Rhee JS. 1999. Identification of the tliDEF ABC transporter specific for lipase in Pseudomonas fluorescens SIK W1. J. Bacteriol. 181: 1847-1852.

30. van Bloois E, Winter RT, Kolmar H, Fraaije MW. 2011. Decorating microbes: surface display of proteins on Escherichia coli. Trends Biotechnol. 29: 79-86.

31. Yang Z, Liu Q, Wang Q, Zhang Y. 2008. Novel bacterial surface display systems based on outer membrane anchoring elements from the marine bacterium Vibrio anguillarum. Appl. Environ. Microbiol. 74: 4359-4365. 